\title{
Relações dialógicas no letramento midiático
}

\author{
Dialogical relations in media literacy
}

\author{
Vlamir Marques Duarte* \\ Universidade Federal da Paraíba \\ João Pessoa, Paraíba \\ Isabella Chianca Bessa Ribeiro do Valle** \\ Universidade Federal da Paraíba \\ João Pessoa, Paraíba
}

Resumo: Vivemos na sociedade das mídias na qual a imagem, tanto verbal quanto audiovisual, convive lado a lado constituindo-se como elementos que norteiam nossas vivencias e escolhas para a construção da nossa percepção da sociedade e da vida. Este artigo objetiva analisar a importância do letramento midiático, do ver uma imagem e descobrir os significados nela contidos, compreendendo seus vários discursos como prática social. Para tanto, abordamos a ideia de 'constância perceptiva', discutida no segundo capítulo do livro A Imagem, de Aumont (1993), sob a luz do dialogismo Bakhtiniano (1992), trazendo-o da esfera literária à visual. Concluímos, portanto, que o letramento midiático é uma construção social cuja contribuição primordial está centrada na escola que, como construtora do saber institucionalizado, não deve permanecer alheia às influências socioculturais inerentes à contemporaneidade.

Palavras-Chave: Dialogismo. Multiletramento. Letramento midiático. Constância perceptiva. Alfabetização audiovisual.

Abstract: We live in the media society in which both verbal and audiovisual image coexist side by side constituting themselves as elements that guide our experiences and choices for the construction of our perception about society and life. This article aims to analyze the importance of media literacy, to see an image and to discover the meanings contained therein, understanding its various discourses as social practice. To that end, we approach the idea of 'perceptive constancy', discussed in the second chapter of Aumont's (1993) 'The Image', in the light of Bakhtinian dialogism (1992), bringing it from the literary sphere to the visual. We conclude, therefore, that media literacy is a social construction whose primary contribution is centered on the school that, as a constructor of institutionalized knowledge, must not remain oblivious to the sociocultural influences inherent in contemporaneity.

Keywords: Dialogism. Multiletrament. Media literacy. Perceptive constancy. Audiovisual literacy.

\footnotetext{
* Mestrando pelo Programa de Pós-Graduação em Comunicação da Universidade Federal da Paraíba. Email: vlamir10@hotmail.com.

** Professora Doutora - Programa de Pós-Graduação em Comunicação - Departamento de Comunicação - Universidade Federal da Paraíba. E-mail: bela.valle.ufpb@gmail.com.
} 


\section{INTRODUÇÃO}

A falta de formação à interpretação crítica, especialmente em relação a obras audiovisuais, pode ser considerada como um tipo de analfabetismo (RODRIGUES, 2014), o que contribui para que milhões de indivíduos lidem com conteúdos audiovisuais de forma despreparada, sem um devido olhar que seja capaz de contextualizar ou de levantar questões relevantes que estejam além do entretenimento; em outras palavras, sem um olhar crítico que permita que se observe e descubra elementos não mostrados explicitamente.

O uso da linguagem visual/midiática na construção de sentidos molda o tecido sociocultural, sobretudo no Brasil, onde a televisão tem lugar de destaques nos lares (GANDRA, 2018), sendo dispositivo fundamental à informação, diversão e até a debates políticos. (ROCHA; INFANTE, 2018).

Neste início de século XXI, temos dedicado mais tempo à linguagem midiática por meio de uma enorme variante de novos modos de acesso à veiculação de imagens que nos foi disponibilizado, principalmente por vídeos compartilhados nas redes sociais na internet, plataformas como o YouTube ${ }^{1}$ ou canais de TV a cabo. Peças videográficas, profissionais ou amadoras, têm registrado situações, ângulos e perspectivas da realidade que antes eram expostas pelo cinema ou televisão em volume e condições de acesso infinitamente menor. Esta popularização de dispositivos capazes de capturar e compartilhar o quotidiano tem cooperado, inclusive, na produção jornalística (BELL, 2016).

Particularmente, as ficções televisuais seriadas passaram a atingir um público gigantesco através da propagação dos canais de TV a cabo e da chegada de serviços de streaming ${ }^{2}$, como a Netflix e a Amazon, que potencializaram ainda mais este fenômeno: muitas séries de sucesso estrondoso transitam exclusivamente por este meio e, não raras vezes, são encontradas para download através de sites e programas de Peer-to-Peer ${ }^{3}$, alcançando um incontável número de espectadores.

Diante desta nova dimensão de produção e distribuição de conteúdo midiático, cabe refletirmos sobre a recepção deste material, como se dá o processo de compreensão da linguagem (tele) visual do século XXI, o que pode nos apoiar numa educação crítica, desconstruindo ideologias vinculadas em imagens e mídias.

\section{LETRAMENTO}

Cabe aqui fazermos uma distinção entre alfabetização e letramento, uma vez que tais termos ainda são confundidos pelas pessoas. Podemos compreender a alfabetização como a aprendizagem da leitura e da escrita, sem que haja a apropriação das práticas sociais que demandam tal condição, conforme a definição de Magda

\footnotetext{
${ }^{1}$ Plataforma online de compartilhamento de vídeos.

2 Todo o conteúdo multimídia que possa ser visto ou ouvido sem precisar fazer download.

${ }^{3}$ Redes de computadores onde cada usuário funciona tanto como cliente quanto como servidor, permitindo compartilhamentos de serviços e dados Ex.: Torrents.
} 
Becker Soares em entrevista publicada pelo Canal Futura em sua página no Youtube: "aquisição do sistema convencional de escrita é a alfabetização e o desenvolvimento de habilidades de uso desse sistema em atividades de leitura e escrita, nas práticas sociais que envolvem a língua escrita, o letramento" (SOARES, 2013).

Rodrigues (2014, p. 92), em seus estudos acerca do ensino da disciplina de Artes Visuais, argumenta que "a alfabetização não deve pertencer apenas ao domínio das 'letras'. Devemos expandir tal noção, chegando ao conceito de 'letramento'." Com referência à alfabetização/letramento midiático, encontramos em Rodrigues (2014, p. 93):

Podemos entender alfabetização como o aprendizado das bases de uma linguagem e letramento como o aprendizado das práticas sociais simbólicas, das quais nos utilizamos a partir do uso fluente da língua. $\mathrm{O}$ mesmo acontece com a leitura de uma imagem vinculada na mídia. Por exemplo, quando vemos uma propaganda na televisão, não paramos para analisar que cores são utilizadas, o arranjo das figuras no espaço, o número de figuras e etc.: esses pontos estão ligados a uma alfabetização imagética. Se por outro lado, analisarmos as práticas discursivas de uma propaganda, os significados sugeridos e possíveis, as partes economicamente envolvidas na confecção e veiculação desta propaganda, estaremos próximos do que chamamos, aqui, de letramento midiático (RODRIGUES, 2014, p. 93).

Portanto, para compreender as significações do mundo que nos cerca - e que é fortemente imagético - devemos perguntar: qual o significado do que vemos?

Com a inserção de tablets, smartphones e notebooks no contexto social, em especial no âmbito escolar, discute-se a teoria dos multiletramentos, ou seja, a concepção de que para cada contexto é necessário um letramento específico (o que não significa que tais letramentos não se articulem entre si). Assim, no contexto midiático, pode-se defender a ideia da implementação de todas as mídias, principalmente as digitais, na formação de cidadãos críticos. A alfabetização tem passado, então, a exigir diferentes níveis de letramento (visual, auditiva, tátil, emocional, digital etc.) na constituição social dos cidadãos deste novo século. Ser multiletrado é requisito cada vez mais incentivado nesta formação educacional de indivíduos, como se norteia a Competência Geral 5 da BNCC (Base Nacional Comum Curricular), que destaca:

Compreender, utilizar e criar tecnologias digitais de informação e comunicação de forma crítica, significativa, reflexiva e ética nas diversas práticas sociais (incluindo as escolares) para se comunicar, acessar e disseminar informações, produzir conhecimentos, resolver problemas e exercer protagonismo e autoria na vida pessoal e coletiva. (BRASIL, 2019, p. 9).

Entendemos que ler extrapola o conceito de decifrar os sinais gráficos da escrita. A construção de significações requer alfabetização letral, política, emocional, cívica e, num mundo onde somos bombardeados por imagens, podemos dizer que a alfabetização visual (e midiática, por conseguinte) é fundamental.

Aumont (1993, p. 78), defende que as imagens são sempre produzidas com algum fim (de propaganda, de informação, religiosos, ideológicos em geral) e que funcionam como vínculo entre o espectador e a realidade. Perceber e compreender 
uma imagem é, também, um processo linguístico, sugestionado pela forma de recepção e de constituição do projeto imagético.

Ler uma imagem é participar da mensagem que ela transmite. Ainda segundo Aumont (1993, p. 81), o espectador é "parceiro ativo da imagem, emocional e cognitivamente (e também como organismo psíquico sobre o qual age a imagem por sua vez)." Portanto, para que esta leitura ocorra, faz-se necessário que o espectador compreenda a mensagem nela contida, compreensão esta que depende, dentre outros fatores, do repertório prévio de quem observa.

Para se ler uma obra midiática, como as ficções televisuais seriadas, por exemplo, podemos evocar o pensamento de Gombrich (apud AUMONT, 1993, p. 82) que nos ensina que, diante de uma imagem, recorremos a uma "reserva de formas de objetos e de arranjos espaciais memorizados: a Constância Perceptiva é a comparação incessante que fazemos entre o que vemos e o que já vimos. ". Contudo, há que ser dito que sem que se seja multiletrado torna-se impossível fazer certas associações para uma leitura plena e a mensagem transmitida pode ser compreendida não completamente. O repertório particular de cada espectador influencia diametralmente a leitura do imagético.

Nesse sentido, a construção dos multiletramentos exigidos para a compreensão da multiplicidade de gêneros textuais que circulam nas diversas esferas de atuação humana, destaca-se o papel preponderante que a escola tem de contribuir para que os estudantes tenham acesso tanto às tipologias textuais como pelo desenvolvimento das habilidades de leitura destes a fim de preparar os jovens ou adultos para o exercício pleno da cidadania, conforme apregoam alguns dos documentos norteadores da educação.

Com relação à leitura dos textos audiovisuais, Thiel e Thiel (2009, p. 12) preponderam que "ensinar a olhar, ver, contemplar e perscrutar o mundo à nossa volta faz parte da tarefa do educador" e, posteriormente, as mesmas autoras acrescentam que "a leitura e a compreensão de diferentes linguagens, expressas em variados suportes, constituem formas de letramento".

A ilustração a seguir exemplifica nosso pensamento:

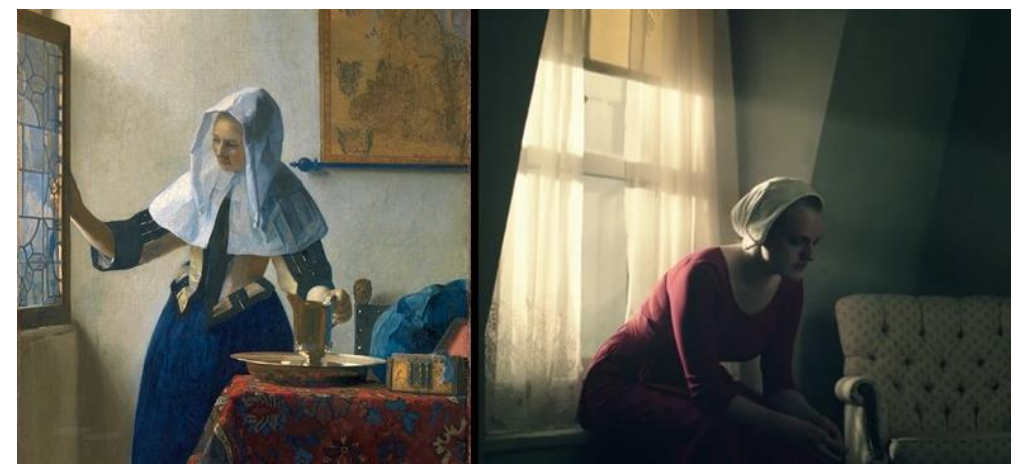

Figuras 1 e 2: Pintura Moca com Jarra de Água, de 1662, do holandês Johannes Vermeer (à esquerda) e frame do primeiro episódio da temporada 01 de The Handmaid's Tale, exibida em 2018 (à direita). 
Fonte: Figura 1 - Acervo do Metropolitan Museum of Art, na cidade de Nova Iorque, Estados Unidos. Figura 2 - Frame capturado aos 55m36s do episódio Offred da série The Handmaid's Tale, escrito por Bruce Miller e dirigido por Reed Morano, baseado no livro de Margareth Atwood.

$\mathrm{Na}$ busca por retratar a angústia da personagem protagonista da série The Handmaid's Tale (em português, O Conto da Aia), a diretora Reed Morano, responsável pelos três primeiros episódios da primeira temporada da série, procurou inspiração nas obras do pintor holandês Johannes Vermeer, do século XVII para compor a atmosfera.

Segundo matéria publicada pelo jornalista Peio H. Riaño no site El Español (2018), Morano quis representar o "silêncio asfixiante" e a "atmosfera densa" do confinamento ao qual a protagonista é submetida, tendo encontrado a equivalência perfeita nas representações de Vermeer sobre o "estilo de vida oprimido das mulheres burguesas do século XVII." Na leitura de Riaño, "a série se afastou das estridências, do palavreado, da ação e se concentrou na construção a partir do talento visual, dos espaços, dos objetos e da luz."

A Constância Perceptiva ou o diálogo entre a imagem e o espectador da série The Handmaid's Tale, diante desta cena, só será plena caso haja o conhecimento prévio de que Vermeer foi a fonte de inspiração. Ainda assim, a relação dialógica se estabelecerá de qualquer forma, pois a constância perceptiva é incessante, como nos ensina Gombrich.

O multiletramento, neste caso, seria responsável por uma leitura mais acurada, mais crítica, mais rica em informações. Então, deduzimos que, para a plena leitura de uma obra audiovisual, o multiletramento é essencial. De outro modo, a preciosidade de circunstâncias passa despercebida.

\section{DIALOGISMO}

Dialogismo ou relações dialógicas é um conceito que remonta aos estudos do texto apregoado pelo russo Mikhail Mikhailovich Bakhtin para se referir às relações entre leitor e texto. A obra de Bakhtin (1992) que aborda, entre outros conceitos linguísticos, o de dialogismo, é mais comumente aplicada a estudos literários. Entretanto, se partirmos da premissa de que linguagem é uma instância social, histórica e ideológica, onde os sujeitos se constituem, é razoável deslocarmos este estudo a todas as outras possibilidades de linguagem, como a midiática.

O conceito bakhtiniano de dialogismo aborda, basicamente, a noção de recepção/compreensão ativa, ou seja, o diálogo que se estabelece entre emissor e receptor, e que podemos dilatar para 'diálogo entre a imagem e o espectador' sem prejuízo algum. Tudo que se refere a texto verbal, neste caso, podemos aplicar a texto (áudio)visual:

O diálogo, no sentido estrito do termo, não constitui, é claro, senão uma das formas, é verdade que das mais importantes, da interação verbal. Mas pode-se compreender a palavra 'diálogo' num sentido mais amplo, isto é, não apenas 
como a comunicação em voz alta, de pessoas colocadas face a face, mas toda comunicação verbal, de qualquer tipo que seja. O livro, isto é, o ato de fala impresso, constitui igualmente um elemento da comunicação verbal. (BAKHTIN, 1992, p. 123).

Uma obra videográfica, assim como uma literária, postula uma atitude responsiva. A construção de sentidos, quando se assiste a uma obra audiovisual, vídeo, filme, telenovela e similares, é, igualmente, um diálogo estabelecido entre nós e a obra, o qual se desenvolve a partir do ato de ver que, segundo Thiel e Thiel (2009, p. 14) "sugere observar, refletir e julgar.". Para as autoras, "quando vemos, não só captamos o que quer que seja, mas, principalmente, construímos julgamentos e ponderamos sobre o que é visto" (THIEL, 2009, p. 14).

Em outras palavras, Bakhtin e Gombrich comungam da mesma noção sobre como os diálogos entre obra e receptor constituem o indivíduo, tendo um nomeado o fenômeno de dialogismo e outro de constância perceptiva, sendo o segundo exclusivo para o âmbito imagético e midiático.

Segundo Rodrigues, a análise crítica de uma mensagem em uma obra, seja ela literária, imagética ou midiática, está no nível do letramento. Neste nível, onde a leitura se dá mais na esfera psicológica, buscamos solucionar "as forças discursivas que operam na obra de arte, multiplicando as interpretações críticas sobre mensagens dos trabalhos artísticos." (RODRIGUES, 2014, p. 94). Para que isto ocorra, no entanto, segundo Rodrigues, é necessária a prévia alfabetização, que seria uma instância mais formalista de análise.

Deduzimos então que o dialogismo (interno) do espectador diante de uma obra audiovisual ocorre em dois processos distintos, a saber: Analítico (alfabetização) - a percepção dos elementos mais óbvios numa composição fílmica. Ocorre a nível coletivo. Crítico (letramento) - a percepção mais reflexiva e abstrata, como das práticas sociais simbólicas. Ocorre a nível particular.

Estes seriam os processos basilares do dialogismo - ou da constância perceptiva - de espectadores na linguagem midiática. As respostas, internas ou externas, ao que se apresenta na tela, transitam (teoricamente) por estes níveis responsivos do indivíduo.

Aumont (1993, p. 90) nos lembra, no entanto, que "a imagem é, pois, tanto do ponto de vista de seu autor quanto de seu espectador, um fenômeno ligado também à imaginação.” Isto é:

A atividade do espectador diante da imagem consiste em utilizar todas as capacidades do sistema visual (em especial suas capacidades de organização da realidade) e em confrontá-las com os dados icônicos precedentemente encontrados e armazenados na memória sob forma esquemática. Ou seja, a parte do espectador, nessa abordagem, é uma combinação constante de 'reconhecimento' e de 'rememoração'. (AUMONT, 1993, p. 90).

Podemos contextualizar o acima citado à luz do filme A Chegada (The Arrival, EUA/2016), cuja mensagem superficial é sobre o contato com alienígenas que 


\section{Revista \\ ACor das Letras}

chegam na Terra e a tentativa de comunicação com eles através de uma linguista humana.

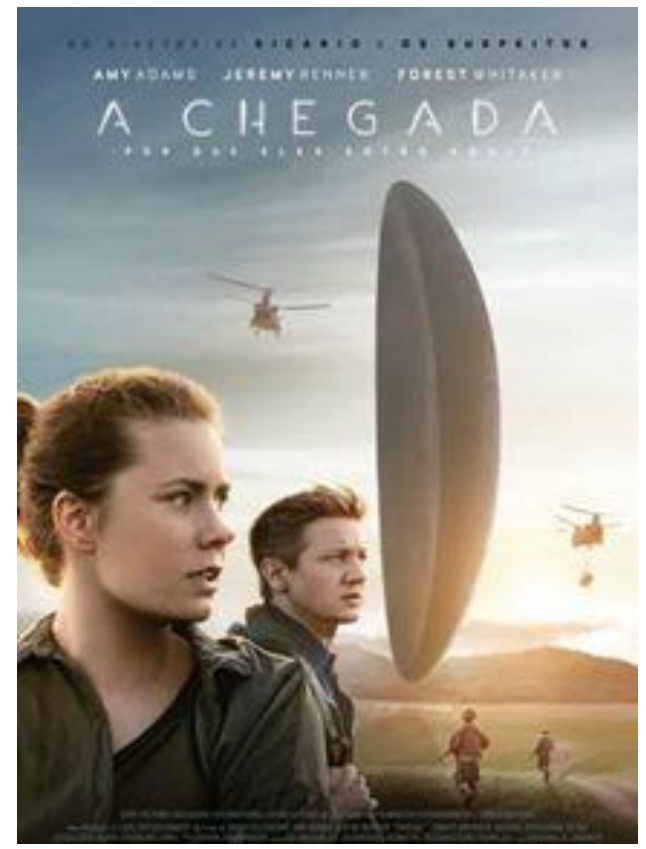

Figura 3 - cartaz do filme A Chegada (Estados Unidos/Canadá, 2016 - direção: Denis Villeneuve. Produção: Shawn Levy. Distribuição: Paramount Pictures. 116 minutos)

As relações dialógicas que os espectadores deste filme estabelecem são tão variadas quanto seus repertórios. Para alguns, trata-se de uma parábola sobre como a linguagem é capaz de afetar nossos pensamentos e determinar a forma como vemos e nos relacionamos com o mundo (Determinismo Linguístico). Para outros, trata-se das complexidades intelectuais e emocionais diante do desconhecido, como, por exemplo, nossa inabilidade de comunicação com estrangeiros.

Há mais sendo dito neste filme do que uma simples sinopse possa contar: A Chegada, assim como qualquer outro filme, conduz o espectador com algum letramento a mergulhar na narrativa e interpretar, associar, desvendar, questionar-se criticamente sobre o que vê na tela, recorrendo ao seu repertório sociocultural para encontrar um sentido maior para a obra.

O reconhecimento e rememoração, admitidos por Aumont como atividade interpretativa constante do espectador, são os gatilhos no processo dialógico de uma obra audiovisual.

Então, desta forma, temos exemplificada a ocorrência do dialogismo em nível analítico (coletivo) e crítico (particular), sendo o primeiro a noção da narrativa como ela se apresenta em sua, digamos, superfície (uma ficção científica sobre o contato com seres extraterrestres) e o segundo uma observação crítica do núcleo da mensagem (que varia de acordo com o repertório e níveis de letramento de cada espectador). 


\section{CONSIDERAÇÕES FINAIS}

Diante de tudo aqui exposto, é razoável admitirmos a necessidade de formação crítica dos cidadãos através da construção do multiletramento, que deve se iniciar no seio familiar, e a partir da idade escolar, no contexto educacional.

A partir das reflexões feitas neste trabalho, constatamos a indispensabilidade de um letramento midiático que enriqueça a criticidade além da mera alfabetização. A prática de ler uma obra midiática em nível mais profundo deve ser estimulada, pois se trata de uma prática social diária exercida desde a mais tenra idade.

O desenvolvimento da linguagem midiática deve ser encarado por educadores como um processo cognitivo fundamental, tanto quanto a linguagem escrita. $\mathrm{O}$ consumo de tecnologia midiática tem ocorrido cada vez mais cedo: não raras vezes presenciamos crianças acessando conteúdo através de tablets e celulares. Esta tecnologia tem, certamente, papel de destaque na formação destes cidadãos.

Saber analisar e avaliar conscientemente as mensagens que nos são transmitidas é ter o poder de evitar a manipulação e a indução ideológica, ainda mais em tempos onde vemos fenômenos da comunicação, como as Fake News ${ }^{4}$, habitarem o cotidiano das pessoas desde telejornais a campanhas políticas.

Contudo, esta reflexão finda por despertar a questão da formação de profissionais habilitados para a tarefa de letrar visual e midiaticamente. Que caberia ser desenvolvida em um próximo artigo: quem estaria apto a tal tarefa?

\section{REFERÊNCIAS}

AUMONT, Jacques. A imagem. Tradução: Estela dos Santos Abreu e Cláudio C. Santoro. Campinas/SP: Papirus, 1993 - (Coleção Ofício de Arte e Forma).

BAKHTIN, M. Marxismo e Filosofia da Linguagem. 6. ed. São Paulo: Hucitec, 1992.

BELL, Fergus. Como lidar com notícias e vídeos produzidos por amadores. 15 de mar. de 2016. Disponível em: < http://observatoriodaimprensa.com.br/jornalismo-na-internet/como-lidar-comnoticias-e-videos-produzidos-por-amadores/>, acesso em 17 de set. de 2019. BRASIL. Base Nacional Comum Curricular (BNCC). O que é a BNCC. Brasília, MEC/CONSED/UNDIME, 2019. Disponível em: < http://basenacionalcomum.mec.gov.br/images/BNCC_EI_EF_110518_versaofinal _site.pdf>, acesso em: 18 de set. de 2019.

GANDRA, Alana. Pesquisa diz que, de 69 milhões de casas, só $2,8 \%$ não têm TV no Brasil. 22 de fev. de 2018. Disponível em: $<$ http://agenciabrasil.ebc.com.br/economia/noticia/2018-02/uso-de-celular-e-

\footnotetext{
${ }^{4}$ Termo em inglês que se tornou popular em todo o mundo para denominar informações falsas que são publicadas, principalmente, em redes sociais.
} 
acesso-internet-sao-tendencias-crescentes-no-brasil $>$, acesso em 17 de setembro de 2019.

HULU. The Handmaid's Tale. Disponível em: <https://www.hulu.com/press/show/the-handmaids-tale/>, acesso em 18 de set. de 2019.

RIAÑO, Peio H. Vermeer, en la sombra (y la luz) de 'The Handmaid's Tale'. 11 de julho de 2018.2 Disponível em: <https://www.elespanol.com/cultura/arte/20180711/vermeer-sombra-luz-thehandmaids-tale/321468832_0.html>, acesso em 20 de abril de 2019.

ROCHA, Matheus; INFANTE, Larissa. Televisão ainda é mais decisiva que internet na escolha de votos, dizem pesquisas. 02 de out. de 2018. Disponível em: <https://epoca.globo.com/televisao-ainda-mais-decisiva-que-internet-naescolha-de-votos-dizem-pesquisas-23121016>, acesso em 17 de set. de 2019.

RODRIGUES, Wallace. Letramento imagético e midiático em arte-educação. Revista Conhecimento \& Diversidade, Niterói, n. 12, p. 90-101 jul./dez. 2014. PDF. SOARES, Magda. Métodos de Alfabetização. 2013. (15m21s). Entrevista - Canal Futura. Disponível em: <https://www.youtube.com/watch?v $=\mathrm{mAOXxBRaMSY}>$, acesso em 22 de abril de 2019.

THE ARRIVAL. A Chegada. Direção: Denis Villeneuve, Produtor: Shawn Levy. Estados Unidos/Canadá: Paramount Pictures, 2016. 1 dvd (116min.) Disponível em: < https://www.paramount.com/movies/arrival>, acesso em 18 de set. de 2019.

THIEL, Grace Cristiane: THIEL, Janice. Movie Takes; a magia do cinema na sala de aula. Curitiba: Aymará, 2009. 